\title{
DETECTION OF MULTI-DRUG RESISTANT SALMONELLA FROM MILK AND MEAT IN BANGLADESH
}

\author{
M. A. Rahman ${ }^{1,2}$, A. K. M. A. Rahman ${ }^{1}$, M. A. Islam $^{3}$ and M. M. Alam ${ }^{1 *}$ \\ ${ }^{1}$ Department of Medicine, Faculty of Veterinary Science, Bangladesh Agricultural University, Mymensingh-2202, \\ Bangladesh; ${ }^{2}$ Department of Medicine, Surgery and Obstetrics, Patuakhali Science and Technology University, \\ Babugonj, Barisal, Bangladesh. ${ }^{3}$ Department of Microbiology and Hygiene, Bangladesh Agricultural University, \\ Mymensingh-2202, Bangladesh
}

\begin{abstract}
This study was conducted to investigate the prevalence of Salmonella spp. in milk, chicken meat and beef and to determine the multi-drug resistance (MDR) profile of Salmonella spp. in Mymensingh and Gazipur districts, Bangladesh. A total of 169 samples of milk $(n=108)$, chicken meat $(n=51)$ and beef $(n=10)$ were collected from Bangladesh Agricultural University (BAU) dairy farm, American dairy farm, Gazipur and different small dairy farms of municipal area during July 2016 to June 2017. Salmonella spp. were isolated on various selective agar media such as: Salmonella-Shigella (SS) agar, Xylose-Lysine Deoxycholate (XLD) agar, Eosine-Methylene Blue (EMB) agar. Identification of Salmonella spp. was done by colony characteristics, Gram staining, biochemical test and Polymerase Chain Reaction (PCR). Multi-drug resistant Salmonella spp. was detected by disc diffusion test using 10 commonly used antibiotics. The overall prevalence of Salmonella spp. in all food samples was $21.89 \%$. A total of 29 (56.86\%) chicken meat, $02(1.85 \%)$ milk, and $06(60 \%)$ beef samples were Salmonella spp. positive. Antibiogram study showed that an overall $89.19 \%$ of Salmonella spp. was found multi-drug resistant. Specifically $100 \%, 66.67 \%$ and $93.10 \%$ of the Salmonella spp. isolates originated from milk, beef and chicken meat respectively were multi-drug resistant. The result of this study suggests that MDR Salmonella spp. is prevalent in the milk and meat which might cause public health hazard if proper hygienic measures are not undertaken at farm and marketing level.
\end{abstract}

Keywords: Salmonella, milk, beef and chicken meat, antibiogram, multidrug resistance, PCR.

\section{INTRODUCTION}

A wide range of pathogens play a role in foodborne diseases, most of which are of animal origin and remain as carriers in healthy food animals from which they spread to foods of animal origin and act as most important vehicles of foodborne infections (S'anchez-Vargas et al., 2011). Among the pathogens, Salmonella is considered the most prevalent foodborne pathogen worldwide and has long been recognized as an important zoonotic bacterium of economic significance in animals and humans (Carrasco et al., 2012) mainly in the developing countries.

Consumption of raw or unsafe food, cross-contamination, improper food storage, poor personal hygiene practices, inadequate cooling and reheating of food items, and a prolonged time lapse between preparing and consuming food items were mentioned as contributing factors to an outbreak of salmonellosis in humans. The ubiquity of Salmonella isolates creates a persistent contamination hazard in all raw foods (Carrasco et al., 2011) and also in animal-origin food products, which are often implicated in sporadic cases and outbreaks of human salmonellosis (Tadesse, 2014).

The prevalence of foodborne Salmonella infections has increased dramatically in Bangladesh during the past few years (Al-Salauddin et al., 2015; Islam et al., 2016; Munsi et al., 2016). The prevalence of Salmonella in meat and market milk has been reported by several authors and the frequency of detection ranges from $6.79 \%$ to $97.6 \%$ (Ramya et al., 2012) in chicken meat and $0.17 \%$ to $28.6 \%$ (Tajbakhsh et al., 2012) in raw milk in India and $21.1 \%$ in poultry in Bangladesh (Mahmud et al., 2011).

Antibiotic-resistant Salmonella infections in both human and animal are universal concerns, particularly in developing countries where the risk of infection is high because of unhygienic living conditions close contact and sharing of houses between animals and humans (Feasey et al., 2012). Antimicrobial-resistant Salmonella spp. have been isolated from different foods of animal origin around the world, which is attributed to the inappropriate use of antimicrobials as therapeutic or prophylactic agents in human and veterinary medicine, as well as the use of growth promoters in animal production (WHO, 2012). However, the sources and transmission routes of Salmonella in developing countries are poorly understood due to the lack of coordinated national epidemiological surveillance systems (Aferstein, 2003).

*Corresponding e-mail address: asamahbub2003@yahoo.com 


\section{Rahman and others}

There are reports of high prevalence of resistance in Salmonella isolates from Bangladesh (Hasan et al., 2014). Studies conducted in different parts of our country have demonstrated the presence of Salmonella in human beings (Nesa et al., 2011) and in different food animals and food products (Al-Salauddin et al., 2015; Rahman et al., 2004). However, there is scant information on the prevalence of foodborne Salmonella spp. and MDR in different food items such as chicken meat in Mymensingh (Al-Salauddin et al., 2015) and in Gazipur (Rahman et al., 2004). But no report on the prevalence of Salmonella spp. in beef from Mymensingh district as per literature review. Therefore, this study reports the presence of Salmonella including its antimicrobial-resistant profiles in foods of animal origin like chicken meat, beef and milk in Mymensingh and Gazipur districts.

\section{MATERIALS AND METHODS}

\section{Study area and collection of samples}

The samples were collected randomly from farms and local markets situated in Mymensingh and Gazipur district of Bangladesh. A total of 169 samples comprised of poultry meat $(n=51)$, beef $(n=10)$ and milk $(n=108)$ samples were tested from July 2016 to December 2017. Aseptically collected meat samples were placed in sterile plastic bags and transported to the Department of Medicine using an icebox. Milk samples were collected from Bangladesh Agricultural University (BAU) dairy farm, American dairy farm, Gazipur, and several small dairy farms. Aseptically $8-10 \mathrm{ml}$ of milk was collected in test tube directly from teat of lactating cow and local market and transported to the Department of Medicine using an icebox. Five to ten grams of chicken (breast and cloacal muscle) meat and beef were collected aseptically in zipper bag from local municipal market and transported to the laboratory using ice box.

\section{Sample preparation}

Ten to twenty grams of meat were mixed with $10 \mathrm{ml}$ of peptone $(0.1 \%)$ water then homogenized suspension was prepared using sterilized pestle and mortar.

\section{Isolation and identification of Salmonella}

The homogenized meat suspension (4 to $5 \mathrm{ml}$ ) was inoculated into nutrient broths $(5 \mathrm{ml} /$ test tube), nutrient agar, SS agar, XLD agar and EMB agar). The inoculated media were incubated at $37^{\circ} \mathrm{C}$ for $24 \pm 2$ hours. Culture positive samples were subcultured several times to be pure culture. Gram staining and biochemical tests and sugar fermentation test were performed (Cheesbrough, 1985).

\section{Polymerase chain reaction (PCR)}

The DNA of Salmonella spp. was extracted by heat lysis method with slight modification (Momtaz et al., 2012). The PCR assays were performed to detect Salmonella spp. using primer pairs. The nucleotide sequence (5'-3') for the Salmonella common primer used for this study were: R- ATG TTG TCC TGC CCC TGG TAA GAG and FACT GGC GTT ATC CCT TTC TCT TGG with an amplicon size of 496 bp (Al-Salauddin et al., 2015). Briefly, for the detection of 16SrRNA gene PCR reaction mixture were $25 \mu \mathrm{l}$ consisting of $5.5 \mu \mathrm{l}$ RNAse free water, $12.5 \mu \mathrm{l}$ PCR master mixture (Thermo Scientific, EU), $5 \mu \mathrm{l}$ DNA template, $1 \mu \mathrm{l}(20 \mathrm{pmol})$ primer. The PCR amplification was done by Initial denaturation at $95^{\circ} \mathrm{C}$ for 5 minutes followed by 30 cycle of denaturation at $95^{\circ} \mathrm{C}$ for 30 seconds, annealing at $62^{\circ} \mathrm{C}$ for 1 minute and extension at $72^{\circ} \mathrm{C}$ for 1 minute. The final extension was at $72^{\circ} \mathrm{C}$ for 10 minutes. PCR amplify products were subjected to gel (1.5\% agarose, Takara, Japan) electrophoresis with ethidium bromide fluorescence (100 v for 30 minutes) and visualized in gel documentation system via UV transilluminator $(302 \mathrm{~nm})$.

\section{Antimicrobial susceptibilty test}

Antimicrobial susceptibility of Salmonella spp., was performed by the disc diffusion according to the guidelines

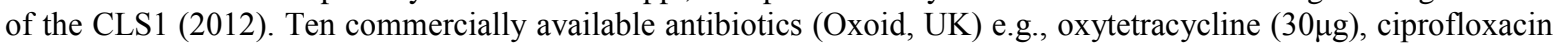
$(5 \mu \mathrm{g})$, gentamicin $(10 \mu \mathrm{g})$, erythromycin, $(15 \mu \mathrm{g})$, azithromycin $(15 \mu \mathrm{g})$, sulphonamide-trimethoprim $(25 \mu \mathrm{g})$, neomycin $(10 \mu \mathrm{g})$, amoxicillin $(10 \mu \mathrm{g})$, doxycycline $(10 \mu \mathrm{g})$ and amikacin $(30 \mu \mathrm{g})$ were used for antibiogram study.

\section{RESULTS}

Salmonella spp. were isolated and identified based on culture, staining and biochemical characteristics. Salmonella spp., produced turbid growth on nutrient broth (Figure 1) and smooth white to grayish white colony on nutrient agar with peculiar fetid odor, pink colonies on EMB agar and black centered colonies on SS agar (Figure 2) and XLD agar (Figure 3). On Gram staining Salmonella spp., were found Gram negative, small rod and arranged as single or paired. Among five basic sugars only dextrose, maltose and mannitol were fermented with the production of acid and gas but lactose and sucrose were not fermented by most of the isolates. 
Salmonella spp. were detected from different food sample the overall prevalence of Salmonella spp. in all food samples was $21.89 \%$. A total of $29(56.86 \%)$ chicken meat, $02(1.85 \%)$ milk, and $06(60 \%)$ beef samples were Salmonella spp. positive (Table 1)

Salmonella spp. was reconfirmed by PCR. The amplicon size of PCR product was $496 \mathrm{bp}$ (16SrRNA gene). One beef and one chicken meat samples have shown Salmonella spp. positive (Figure 5).

The result of antibiotic sensitivity test is shown in Table 2. Salmonella spp. isolated from chicken meat was resistant to erythromycin $(100 \%)$, doxycycline $(79.31 \%)$, sulphonamide-trimethoprim (75.86\%), azithromycin $(72.41 \%)$ and oxytetracycline $(66.67 \%)$ and sensitive to ciprofloxacin $(83.33 \%)$ and gentamicin $(86.21 \%)$. Salmonella spp. isolated from beef samples was resistant to erythromycin $(83.33 \%)$, azithromycin $(83.33 \%)$, oxytetracycline $(66.67 \%)$ and doxycycline $(66.67 \%)$; and sensitive to gentamicin (100\%), neomycin (100\%) ciprofloxacin $(83.33 \%)$, amikacin $(83.33 \%)$. Salmonella spp. isolated from milk samples were $100 \%$ sensitive to gentamicin, neomycin and ciprofloxacin, and $100 \%$ resistant to erythromycin, doxycycline and amoxycilin. Overall 89.19\% isolates of Salmonella spp. were found multi-drug resistant (Table 3, Figure 4). About 100\%, 66.67\% and $93.10 \%$ of the Salmonella spp. isolates originated from milk, beef and chicken meat respectively were multi-drug resistant (resistant to three or more antibiotics).

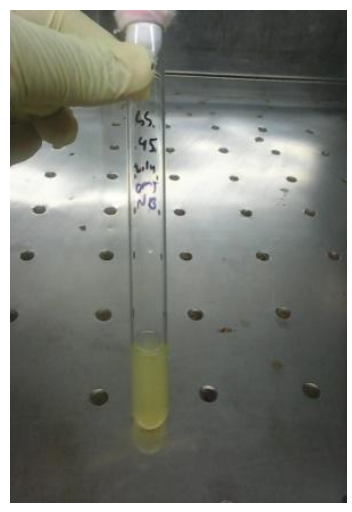

Figure 1. Growth of Salmonella spp. in nutrient broth

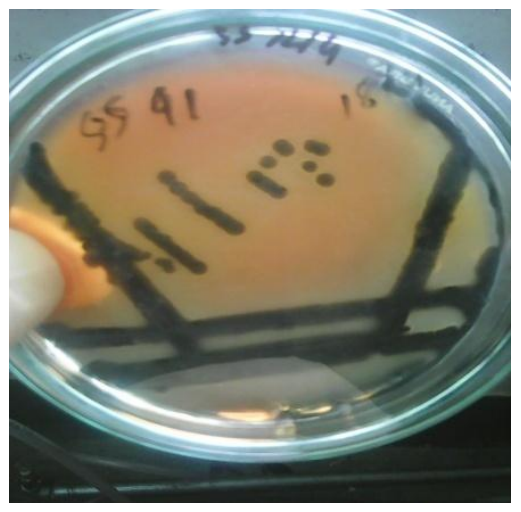

Figure.2. Formation of black centered colony of Salmonella spp. on SS agar.

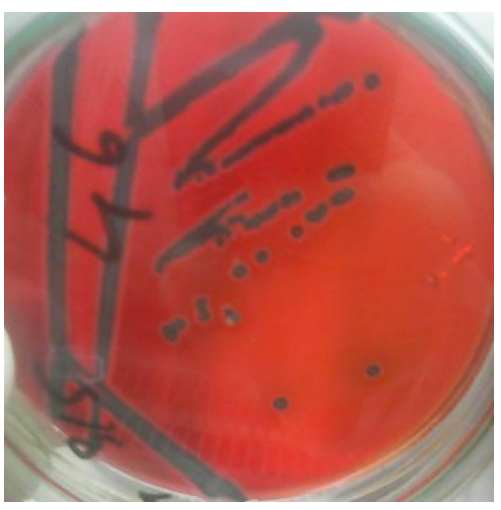

Figure 3. Formation of Black centered single colony of Salmonella spp. on XLD agar

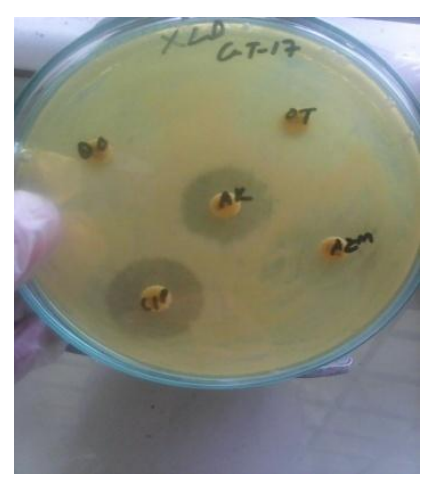

Figure.4. Antibacterial susceptibility test of Salmonella sp on Muller Hinton Agar (recovered from XLD agar).Resistant to Oxytetracycline (OT), Azythromycin (AZM), Doxycycline (DO), and Susceptible to Amikacin (AK), Ciprofloxacin (CIP).

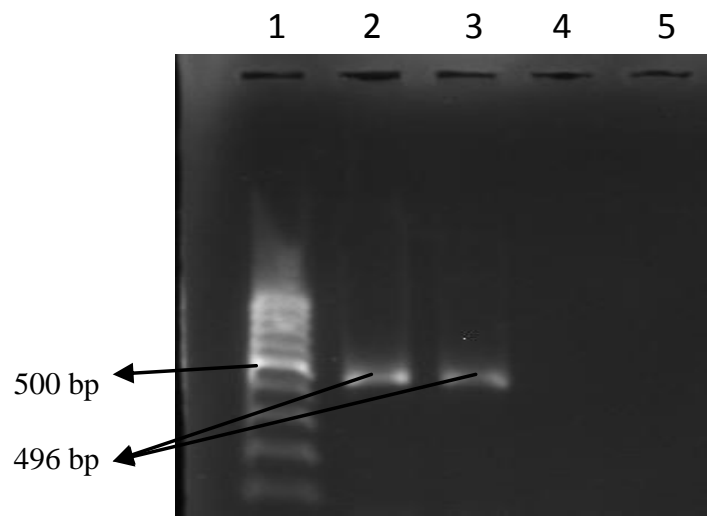

Figure 5. Amplification of PCR product; Lane 1:100 bp ladder, Lane 2 \& 3: Specific for Salmonella spp. (Size-496bp for 16SrRNA gene). Lane $4 \& 5$ negative. 


\section{Rahman and others}

Table 1. Prevalence of Salmonella spp. in food samples

\begin{tabular}{lllll}
\hline Sample & Sample tested & Positive & Prevalence (\%) & $95 \%$ CI \\
\hline Milk & 108 & 02 & 1.85 & $0.32-7.19$ \\
Chicken meat & 51 & 29 & 56.86 & $42.32-70.37$ \\
Beef & 10 & 06 & 60.00 & $27.37-86-31$ \\
Total & 169 & 37 & 21.89 & $16.06-29.03$ \\
\hline
\end{tabular}

Table 2. Antibiogram study of Salmonella spp. isolates from food samples

\begin{tabular}{|c|c|c|c|c|c|c|}
\hline \multirow[t]{2}{*}{ Antibiotics } & \multicolumn{2}{|c|}{ Chicken meat $(n=29)$} & \multicolumn{2}{|c|}{ Milk $(n=02)$} & \multicolumn{2}{|l|}{ Beef $(n=6)$} \\
\hline & $\mathrm{R}=\mathrm{n}(\%)$ & $\mathrm{S}=\mathrm{n}(\%)$ & $\mathrm{R}=\mathrm{n}(\%)$ & $\mathrm{S}=\mathrm{n}(\%)$ & $\mathrm{R}=\mathrm{n}(\%)$ & $\mathrm{S}=\mathrm{n}(\%)$ \\
\hline Ciprofloxacin & $5(17.24)$ & $24(83.33)$ & 0 & $2(100)$ & $01(16.67)$ & $5(83.33)$ \\
\hline Gentamicin & $04(13.79)$ & $25(86.21)$ & 0 & $2(100)$ & 0 & $6(100)$ \\
\hline Erythromycin & $29(100)$ & 0 & $02(100)$ & 0 & $05(83.33)$ & $1(16.67)$ \\
\hline Azithromycin & $21(72.41)$ & $8(27.59)$ & $01(50)$ & $1(50)$ & $05(83.33)$ & $1(16.67)$ \\
\hline $\begin{array}{l}\text { Sulphonamide and } \\
\text { Trimethoprim }\end{array}$ & $22(75.86)$ & $7(24.14)$ & $01(50)$ & $1(50)$ & $02(33.33)$ & $4(66.67)$ \\
\hline Neomycin & $05(17.24)$ & $24(82.76)$ & 0 & $2(100)$ & 0 & $6(100)$ \\
\hline Amoxicillin & $13(44.83)$ & $16(55.17)$ & $02(100)$ & 0 & $02(33.33)$ & $4(66.67)$ \\
\hline Doxycycline & $23(79.31)$ & $6(20.69)$ & $02(100)$ & 0 & $04(66.67)$ & $2(33.33)$ \\
\hline Amikacin & $10(34.48)$ & $19(65.52)$ & - & - & 01(16.67) & $5(83.33)$ \\
\hline Oxytetracycline & $04(66.67)$ & $02(33.33)$ & - & - & $04(66.67)$ & $02(33.33)$ \\
\hline
\end{tabular}

$\mathrm{R}=$ Resistant Salmonella; $\mathrm{S}=$ Sensitive Salmonella

Table 3. Detection of multi-drug resistant Salmonella spp. in food samples

\begin{tabular}{|c|c|c|c|}
\hline Name of samples & $\begin{array}{l}\text { No. of Salmonella } \\
\text { isolated }\end{array}$ & No. of MDR Salmonella & Prevalence of MDR Salmonella (\%) \\
\hline Milk & 02 & 02 & 100 \\
\hline Chicken meat & 29 & 27 & 93.10 \\
\hline Beef & 06 & 04 & 66.67 \\
\hline Total & 37 & 33 & 89.19 \\
\hline
\end{tabular}

\section{DISCUSSION}

The overall prevalence of Salmonella spp. in all food samples was $21.89 \%$ and $56.86 \%$ of chicken meat were positive for Salmonella spp. which is in agreement with Parbati et al. (2017) who isolated $53.33 \%$ Salmonella spp. from poultry and poultry environment; and with the Islam MJ (2016) who isolated 55\% salmonella spp. from healthy poultry and their cloacal swab. But our result differs with the findings of other authors where the range of reported prevalence varied from $18 \%$ to $31.66 \%$ (Barua et al., 2012; Al-Salauddin et al., 2015). Sharma and Das (2016) isolated 43\% Salmonella in chicken carcass at Assam, India. Dallal et al. (2009) reported 21.6\% and 15.7\% Salmonella spp. in unpackaged and packaged chicken meat; $29.4 \%$ and $33.3 \%$ in packaged and unpackaged beef in retail store shop respectively. These variations might be due to source of sample collection, hygienic condition of the farm and personal hygiene of the processors and handlers.

We observed only $1.85 \%$ Salmonella spp. in milk samples. However, Munsi et al. (2015) reported $35.71 \%$ milk samples to be positive for Salmonella typhi in vendor milk and $0 \%$ in brand milk. We have collected milk aseptically from teat directly and the prevalence of Salmonella spp. in our samples was very low because of no intermediate contamination. The high prevalence of Salmonella spp. in vendor milk was probably due to adding contaminated water or unhygienic handling, using contaminated utensils, etc. (Antunes et al., 2003). Among 37 culture positive Salmonella spp., only two samples were confirmed by PCR. Similar findings was also reported by Yadav et al. (2017) where one out of 18 culture positive samples was found to be InvA gene positive (Salmonella 
typhimurium), and 5 samples were turned out as SefA gene positive (Salmonella enteridis). Smilarly, Parimal et al. (2002) also confirmed 92 isolates as PCR positive out of 569 Salmonella positive samples. Salmonella spp. isolated from chicken meat were resistant to Erythromycin (100\%), Doxycycline (79.31\%), sulphonamide-trimethoprim (75.86\%), azithromycin $(72.41 \%)$ and oxytetracycline $(66.67 \%)$ and sensitive to ciprofloxacin $(83.33 \%)$ and gentamicin $(86.21 \%)$. Similar findings had also been reported by other authors (Rahman et al., 2004; Al-salauddin et al., 2015; Obi and Ike, 2015; Parbati et al., 2017; Parvez et al., 2016). Salmonella spp. isolated from beef sample were resistant to erythromycin $(83.33 \%)$, azithromycin $(83.33 \%)$, oxytetracycline $(66.67 \%)$ and doxycycline (66.67\%); and sensitive to gentamicin (100\%), neomycin $(100 \%)$ ciprofloxacin $(83.33 \%)$, amikacin $(83.33 \%)$. Similarly Dallal et al. (2009) also reported Salmonella spp. from beef sample as $100 \%$ resistant to erythromycin and tetracycline; $60 \%$ resistant to sulphamethoxazole, and all isolates were susceptible to ciprofloxacin and gentamicin. Azithromycin is normally used in humans, pet animals and poultry .However, Salmonella isolated form foods of animal origin were found to be resistant to azithromycin. This indicates interspecies transmission of resistance gene which might pose serious public health threats.

Salmonella spp. isolated from milk samples were $100 \%$ sensitive to gentamicin, neomycin and ciprofloxacin, and $100 \%$ resistant to erythromycin, doxycycline and amoxicilin. Other authors also found Salmonella isolates of raw and fermented milk origin as $100 \%$ sensitive to ciprofloxacin and gentamicin and resistant to erythromycin $(85.7 \%)$ and amoxicillin (78.6\%) (Tamba et al., 2016; Munsi et al., 2015).

Multi- drug resistant Salmonella isolates were found in different food samples. Although we did not check the pathogenicity of the isolates, the gene responsible for multi-drug resistance may transfer to consumer via food and results in serious public health hazard. An overall $89.19 \%$ isolates of Salmonella spp. were found to be multi-drug resistant. About $100 \%, 66.67 \%$ and $93.10 \%$ of the Salmonella spp. isolates originated from milk, beef and chicken meat respectively were multi-drug resistant. This MDR result is higher than that of Al-Salauddin et al., (2015) who reported $16.67 \%$ isolates of Salmonella originated from broiler meat as multidrug resistant (MDR); and also higher with the findings of Dallal et al. (2009) who reported $23.5 \%$ of the Salmonella strains as MDR to two or more antibiotic families. These findings showed that MDR in Salmonella spp., prone to increase with the time due to indiscriminate use of antibiotics in dairy and poultry industry, pet animal practice and in human practice in Bangladesh. Rationale use of this drug may prevent development of resistant isolates of Salmonella spp., in future.

\section{CONCLUSION}

The presence of Salmonella spp. in food indicates contamination with polluted water; the improper handling, processing and storage and poor personal hygiene and sanitation. Salmonella isolates of food animal and poultry origin found to be resistant to drugs commonly used in humans like azithromycin. This indicates interspecies transmission of resistance gene which might pose serious public health threats. The antibiogram profile of the isolates will help choosing the most effective antibiotics to treat the diseases conditions caused by Salmonella spp. in cattle and poultry in Bangladesh.

\section{ACKNOWLEDGEMENTS}

The author would like to acknowledge the Ministry of Education, Bangladesh for financial support (Project no.267/2015.MoE) for funding the research.

\section{REFERENCES}

1. Aferstein FK (2003). Foodborne diseases in developing countries: aetiology, epidemiology and strategies for prevention. International Journal of Environmental Health Research 13:161-168

2. Al-Salauddin AS, Hossain MF, Dutta A, Mahmud S, Islam MS, Saha S and Kabir SML (2015). Isolation, identification, and antibiogram studies of Salmonella species and Escherichia coli from boiler meat in some selected areas of Bangladesh. International Journal of Basic \& Clinical Pharmacology 4:999

3. Antunes P, Reu C, Sousa JC, Peixe L and Pestana N (2003). Incidence of Salmonella from poultry products and their susceptibility to antimicrobial agents. International Journal of Food Microbiology 82:97-103.

4. Barua H, Biswas PK, Olsen KEP and Christensen JP (2012). Prevalence and Characterization of Motile Salmonella in Commercial Layer Poultry Farms in Bangladesh. PLoS ONE 7:e35914.

5. Boyd D, Cloeckaert A, Chaslus-Dancla E and Mulvey MR (2002). Characterization of variant Salmonella genomic island 1 multiple resistance regions from serovars Typhimurium DT104 and Agona. Antimicrob. Agents Chemotherapy 46:1714-1722

6. Carrasco E, Morales-Rueda A and Garc'1a-Gimeno RM (2012). Cross-contamination and recontamination by Salmonella in foods: a review. Food Research International 45:545-556 


\section{Rahman and others}

7. Cheesbrough M (1985). Medical laboratory manual for tropical countries $.2^{\text {nd }}$ edition.

8. CLSI (Clinical Laboratory Standard Institute) (2012). Performance standards for antimicrobial disk susceptibility tests: approved standard. 11th edn. Wayne: CLSI Publication M2-A11.

9. Dallal MMS, Tarem M, Gachkar L, Modarressi S, Sanae IM, Bakhtiari R, Yazdi M and Zali M (2009). Characterization of antibiotic resistant patterns of Salmonella serotypes isolated from beef and chicken samples in Tehran. Jundishapur Journal of Microbiology 2:124-131

10. Feasey NA, Dougan G, Kingsley RA, Heyderman RS and Gordon MA (2012). Invasive non-typhoidal salmonella disease: an emerging and neglected tropical disease in Africa. The Lancet 379:2489-2499.

11. Hassan MM, Amin KB, Ahaduzzaman M, Alam M, Faruk MS and Uddin I (2014). Antimicrobial resistance pattern against E. coli and Salmonella in layer poultry. Research Journal of Veterinary Practices 2:30-35.

12. Islam MJ, Mahbub-E-Elahi ATM, Ahmed T and Hasan MK (2016). Isolation and identification of Salmonella spp. from broiler and their antibiogram study in Sylhet, Bangladesh. Journal of Applied Biology \& Biotechnology 4:46-51

13. Mahmud MS, Bari ML and Hossain MA (2011). Prevalence of Salmonella serovars and antimicrobial resistance profiles in poultry of Savar area, Bangladesh. Foodborne Pathogens and Diseases 8:1111-8.

14. Momtaz H, Dehkordi FS, Taktaz T, Rezvani A, Yarali S (2012). Shiga toxin-producing Escherichia coli isolated from bovine mastitic milk: serogroups, virulence factors, and antibiotic resistance properties The Scientific World Journal. Article ID $618709: 1-9$

15. Munsi MN, Sarker NR, Khatun R and Alam MK (2015). Identification and antibiogram study of bacterial species isolated from milk samples of different locations in Bangladesh. Asian Journal of Medical and Biological Research $1: 457-462$

16. Nesa MK, Khan MSR and Alam M (2011). Isolation, identification and characterization of salmonella serovars from diarrhoeic stool samples of human. Bangladesh Journal of Veterinary Medicine 9:85-93

17. Noah DC, Holly LN, Edward DM, Howard WW, Robert WB, Pamela MR and Hargis BM (1993). Genus-specific detection of Salmonellae using the polymerase chain reaction (PCR). Journal of Veterinary Diagnosis. Investigation 5:368-371.

18. Obi OJ and Ike AC (2015). Prevalence and Antibiogram Profile of Salmonellae in Intensively Reared and Backyard Chickens in Nsukka Area, Nigeria. Nigerian Journal of. Biotechnology 30:18-25

19. Parbati P, Sonia A, Ali M Z, Hasna B, Khan MSR and Khatun MM (2017). Isolation, Identification and Antibiogram Study of Salmonella spp. from Poultry Farm Environment. International Journal of Animal Biology 3:5-11

20. Parimal R, Dhillon AS, Lauerman LH, Schaberg DM, Bandli D and Johnson S (2002). Results of Salmonella isolation from poultry products, poultry, poultry environment, and other characteristics. Avian Diseases 4:17

21. Parvej MS, Nazir KHMNH, Rahman MB, Jahan, Khan MFR and Rahman M (2016). Prevalence and characterization of multi-drug resistant Salmonella Enterica serovar Gallinarum biovar Pullorum and Gallinarum from chicken. Veterinary World 9:65-70.

22. Rahman MA, Samad MA, Rahman MB and Kabir SML (2004). In vitro antibiotic sensitivity and therapeutic efficacy of experimental salmonellosis, colibacillosis and pasteurellosis in broiler chickens Bangladesh Journal of Veterinary Medicine 2:99-102.

23. Ramya P, Madhavarao T and Rao LV (2012). The incidence of Salmonella enteritidis in poultry and meat samples by cultural and PCR methods. Veterinary World 5: 541-545.

24. S'anchez-Vargas FM, Abu-El-Haija MA and G'omez- Duarte OG (2011). Salmonella infections: an update on epidemiology, management, and prevention. Travel Medicine and Infectious Disease 9:263-277.

25. Sharma I and Das K (2016). Detection of invA Gene in Isolated Salmonella from Marketed Poultry Meat by PCR Assay. Journal of Food Processing and Technology 7:1-9

26. Tadesse G (2014). Prevalence of human Salmonellosis in Ethiopia: a systematic review and meta-analysis. BMC Infectious Diseases 14, article no. 88.

27. Tajbakhsh M, Hendriksen RS, Nochi Z, Zali MR, Aarestrup FM and Garcia-Migura L (2012). Antimicrobial resistance in Salmonella spp. recovered from patients admitted to six different hospitals in Tehran, Iran from 2007 to 2008. Folia Microbioloca 57:91-97

28. Tamba Z, Bello M and Raji MA (2016). Occurrence and antibiogram of Salmonella spp. in raw and fermented milk in Zaria and environs. Bangladesh Journal of Veterinary Medicine 14:103-10722.

29. WHO (World Health Organization) (2012). The Evolving Threat of Antimicrobial Resistance: Options for Action, WHO, Geneva, Switzerland,

30. Yadav, SK, Ahaduzzaman M, Islam MS, Siddiki and Zonaed AMAM (2017). Isolation and identification of Salmonella spp. from captive ostriches in Bangladesh by InvA gene and SefA gene - specific PCR and detection of their antimicrobial resistance patterns. Annals of Veterinary and Animal Sciences 4:1-7. 